\title{
Role of the Clinical Pharmacist in Detection of Drug Therapy Problems in Critically Inpatients: Experience Report
}

\author{
Gabrielle Mari Rosetti Alves ${ }^{1}$, Fabiana Rossi Varallo ${ }^{1}$, Rosa Camila Lucchetta ${ }^{2}$ and Patricia de Carvalho Mastroianni ${ }^{{ }^{*}}$ \\ ${ }^{1}$ Drugs and Medicines Department of the School of Pharmaceutical Sciences of Universidade Estadual Paulista "Júlio de Mesquita Filho" (UNESP), Brazil \\ ${ }^{2}$ Pharmacy Department of Universidade Federal do Paraná (UFPR), Brazil
}

"Corresponding author: Patricia de Carvalho Mastroianni, Faculdade de Ciências Farmacêuticas - UNESP, Rodovia Araraquara - Jaú, km 1 - CEP: 14801-902, Araraquara - SP, Brazil, Tel: +55 16 3301-6977; Fax: +55 16 3322-0073, +55 16 3301-6960; E-mail: pmastro@fcfar.unesp.br

Received date: July 21, 2014, Accepted date: July 25, 2014, Published date: August 1, 2014

Copyright: ( 2014 Alves GMR, et al. This is an open-access article distributed under the terms of the Creative Commons Attribution License, which permits unrestricted use, distribution, and reproduction in any medium, provided the original author and source are credited.

\begin{abstract}
This is an experience report on clinical pharmacy in New York, United States of America, in a teaching hospital, describing the results of drug therapy monitoring in critically ill patients, as well as interventions to solve or prevent identified drug therapy problems. The cross-sectional study was conducted by the clinical staff at the Surgical Intensive Care Unit during August 20th to 24th, 2012. Blood counts, serum levels of certain antibiotics, microbiological cultures and their antibiotic susceptibility, possible drug interactions, dosage of each drug prescribed and the compatibility between the route of administration and pharmaceutical form were assessed daily through review of electronic medical records. Twenty seven patients were followed up and 16 drug therapy problems were identified: Unnecessary drug therapy (seven), adverse drug reaction (four), needs additional drug therapy (two), noncompliance (two) and dosage too low (one). After evaluation, the drug therapy problems and their pharmaceutical interventions were reported to clinical pharmaceutical responsible for the Surgical ICU, as well as the multidisciplinary team. Further, the clinical outcomes were monitored and interventions were classified as to its acceptance. Data demonstrate that clinical pharmacists can contribute to the security and proper use of medications, as the trigger tools for intensive monitoring helps in early detection of drug therapy problems and patient safety.
\end{abstract}

Keywords: Patient safety; Pharmacovigilance; Drug-related side effects and adverse reactions; Intensive Care Units

\section{Introduction}

Pharmacovigilance is a cross practice to the role of clinical pharmacy, since drug therapy monitoring helps to detect problems related to safety, effectiveness and quality of drugs [1].

According to Cipolle [2], the drug therapy problems are events that prevent or delay patient recovery. The processes for identifying, resolving and preventing drug therapy problems is a mainstay of pharmacotherapy management, also being the scope of postmarketing surveillance of drugs [3].

Studies show that the inclusion of the clinical pharmacist in the intensive care unit reduces mortality 4 and adverse events [4-7], improves clinical outcomes 4 and reduces hospital costs [6-8].

Considering that polypharmacy and the high proportion of drug administration by intravenous contribute to increase the risks associated with the use of medications, drug therapy monitoring in critically ill patients is important [9]. Therefore, this study aimed to describe the results of drug therapy monitoring of critically ill patients, as well as interventions to prevent or resolve identified drug therapy problems.

\section{Materials and Methods}

This is an experience report on clinical pharmacy in New York, United States of America, in a teaching hospital, member of the New
York Presbyterian Health System. The hospital has 651 beds, of those, 27 are for Surgical Intensive Care Unit (ICU), where was developed this report experience. Surgical ICU is intended for all adult patients, in preoperative and postoperative period. Inclusion criteria were all patients in the unit during the study period.

The hospital is certified by the Joint Commission on Accreditation of Healthcare Organizations (JCAHO) and fulfills the Health Insurance Portability and Accountability Act of 1996 (HIPAA), which protects patient identification, preventing their names and personal data of been published. Therefore, in this study patients will be identified by the Medical Record Number (MR \#).

At the Surgical ICU the clinical pharmacy services are developed through reviewing electronic medical records of all patients. For this analysis, we considered all medical records during August $20^{\text {th }}$ to $24^{\text {th }}$, 2012.

Electronic charts were daily monitored to detect possible drug therapy problems. Trigger tools (blood count, serum levels of certain antibiotics, microbiological cultures and their antibiotic susceptibility) were followed up. The staff also evaluated the occurrence of possible drug interactions, dosage of each drug prescribed and the compatibility between the route of administration and pharmaceutical form used.

After reviewing the medical records, clinical rounds were initiated in order to verify the presence of mechanical ventilation, enteral or parenteral nutrition and ability to ambulate. 
Drug therapy problems identified were classified according to their etiology [2] and seriousness [10]. Thus, according to the etiology, drug therapy problems can be classified into:

1. Unnecessary drug therapy: The drug therapy is unnecessary because the patient does not have a clinical indication at this time.

2. Needs additional drug therapy: Additional drug therapy is required to treat or prevent a medical condition.

3. Ineffective Drug: The drug product is not effective at producing the desired response.

4. Dosage too low: The dosage is too low to produce the desired response.

5. Adverse drug reaction: The drug is causing an adverse reaction.

6. Dosage too high: The dosage is too high resulting in undesirable effects.

7. Noncompliance: The patient is not able or willing to take the drug regimen appropriately.

According to the National Council for Medication Error Reporting and Prevention (NCCMERP), an organization that aims develop strategies to assist health professionals to avoid possible medication errors, provides that when the performance of a health professional could lead to inappropriate medication use or harm the user, these events can be classified according to the potential medication errors:

1. Category A: The situation has the ability to lead to a medication error.

2. Category B: A medication error occurred, but was previously identified to the application of the medication.

3. Category C: A medication error occurred, but did not cause harm to the patient.

4. Category D: A medication error occurred, resulting in the need for patient monitoring.

5. Category E: A medication error occurred and contributed temporarily to clinical worsening of the patient. Intervention was required.

6. Category F: A medication error occurred and contributed temporarily to clinical worsening of the patient, resulting in hospitalization or prolongation of hospitalization.

7. Category G: A medication error occurred and may have resulted in permanent damage to the patient.

8. Category H: A medication error occurred causing the need for intervention to sustain life.

9. Category I: A medication error occurred that may have contributed to the patient's death.

After assessment, drug therapy problems and their pharmaceutical interventions were reported to clinical pharmaceutical responsible for Surgical ICU, as well as the multidisciplinary team. Further, the clinical outcomes were monitored and interventions were classified as to its acceptance.

Accepted interventions were considered those in which there was a change of prescription medication in the system. Not accepted interventions were considered those which there were not properly completed or have not been implemented due to the discharge of the patient.

\section{Results}

During the period, 27 patients were followed, whom seven had drug therapy problems and 16 interventions were implemented. The drug therapy problems were classified into unnecessary drug therapy (seven), adverse drug reaction (four), needs additional drug therapy (two), noncompliance (two) and dosage too low (one). The situations identified were classified in the categories A (seven), B (seven) and C (two) from NCCMERP classification (Table 1).

The overall prevalence demonstrates that clinical pharmacy services permeated $26 \%$ of patients in the surgical ICU, in other words, in a proportion of four patients, one required of the clinical pharmacist activity, and could have had clinical complications if there was not a clinical pharmacist seeking improvements to their drug therapies.

Moreover, the prevalence of drug therapy problems demonstrates that for each patient treated by clinical pharmacist were found at least two drug therapy problems liable to intervention.

\section{Discussion}

By convention the JCAHO 2001, patients should not feel pain [11]. However, from this convention, it was observed the increasing use of opioids and also the increased frequency of adverse reactions. Subsequent studies have concerns, security should not restrict the effectiveness of pain management, so therapeutic options with opioids should be available [12].

According to Honiden [13], the pain goals should be individualized to meet the needs of each patient, and for being subjective, the most reliable evaluations require the active participation of the patient. Among patients who cannot communicate, the pain can be inferred from observable behavior through the aid of instruments such as "Behavior Pain Scale" or "Critical Care Pain Observation Tool", but there are limitations due to interpretation.

Most surgical ICU patients reported pain or makes use of opioids during surgery. In these cases, because of published studies warning about the possible adverse reactions, the JCAHO recommends monitoring of them [14-16]. Therefore, in order to monitor the occurrence of adverse reactions caused by opioids, symptoms such as nausea, vomiting, dizziness and sedation should be reported to the multidisciplinary team for treatment.

As the hospital is accredited by the JCAHO, should follow these recommendations, and therefore, patients MR \#4021893, MR \#742896 and MR \#4924432 received pharmaceutical interventions to prevent drug related problems that are common to these drugs and encourage communication between patients, doctors and nurses.

The MR \#4021893 patient received intervention, in order to prevent receive the medicine that was prescribed only for the day of surgery (morphine, fentanyl and ondansetron).

The MR \#742896 patient was receiving two drugs of similar action mechanism, metoprolol and labetalol, which could accentuate the adverse effects of these drugs, in addition to increasing the likelihood of a hypotensive crisis. The perception by the clinical pharmacist and the acceptance of pharmaceutical intervention on the same day may have avoided such drug therapy problems [17-19]. This same patient also had other preventive intervention in order to avoid 
Citation: Alves GMR, Varallo FR, Lucchetta RC, Mastroianni PC (2014) Role of the Clinical Pharmacist in Detection of Drug Therapy Problems in Critically Inpatients: Experience Report. J Pharmacovigilance 2: 139. doi:10.4172/2329-6887.1000139

Page 3 of 6

administration of hydromorphone medication, scheduled only for the surgery day. With the discontinuation of this medication, potentially serious drug related problems may have been avoided, such as hypotension, bradycardia, bronchospasm, among other potential adverse reactions [20].

\begin{tabular}{|c|c|c|c|c|}
\hline $\begin{array}{l}\text { Drug therapy problems } \\
\text { etiology }\end{array}$ & Drug therapy problems & NCCMERP & Pharmaceutical intervention & $\begin{array}{l}\text { Acceptance (reason for not } \\
\text { acceptance) }\end{array}$ \\
\hline \multicolumn{5}{|c|}{ Patient Medical Record 4021893} \\
\hline Unnecessary drug therapy & Ketorolac scheduled & A & $\begin{array}{l}\text { Ask the necessity of NSAIDs. It is } \\
\text { necessary only if the patient feels } \\
\text { pain. Change the status to PRN }\end{array}$ & Not accepted (discharged) \\
\hline Unnecessary drug therapy & $\begin{array}{l}\text { Morphine, fentanyl and ondansetron } \\
\text { scheduled. It should be prescribed } \\
\text { only for the day of surgery }\end{array}$ & B & $\begin{array}{l}\text { Discontinue morphine, fentanyl and } \\
\text { ondansetron }\end{array}$ & Not accepted (discharged) \\
\hline \multicolumn{5}{|c|}{ Patient Medical Record 742896} \\
\hline Unnecessary drug therapy & Droperidol scheduled & $A$ & Change the status to PRN. & Not accepted (discontinued) \\
\hline Unnecessary drug therapy & Metoprolol and labetalol scheduled & $B$ & Discontinue labetalol & Accepted \\
\hline Unnecessary drug therapy & $\begin{array}{l}\text { Hydromorphone scheduled when it } \\
\text { should have been stopped the day } \\
\text { before }\end{array}$ & B & Discontinue hydromorphone & Accepted \\
\hline Noncompliance & Metoprolol bid & $B$ & Change the status to $\mathrm{q} 12 \mathrm{~h}$ & Accepted \\
\hline \multicolumn{5}{|c|}{ Patient Medical Record 4924432} \\
\hline Unnecessary drug therapy & Metoclopramide scheduled & A & $\begin{array}{l}\text { Change the status to PRN or } \\
\text { discontinue it }\end{array}$ & Not accepted (discharged) \\
\hline Adverse drug reaction & $\begin{array}{l}\text { IV pantoprazole prescribed to } \\
\text { patient receiving oral medications }\end{array}$ & A & Change IV pantoprazole to oral & Not accepted (discharged) \\
\hline \multicolumn{5}{|c|}{ Patient Medical Record 4348201} \\
\hline Unnecessary drug therapy & $\begin{array}{l}\text { Scheduled metoprolol and PRN } \\
\text { metoprolol }\end{array}$ & A & Discontinue PRN metoprolol & Accepted \\
\hline Needs additional drug therapy & No stress ulceration prophylaxis & A & Add proton pump inhibitor & Accepted \\
\hline \multicolumn{5}{|c|}{ Patient Medical Record 4918096} \\
\hline Needs additional drug therapy & PRN metoprolol & C & $\begin{array}{l}\text { Change the metoprolol status to } \\
\text { scheduled }\end{array}$ & $\begin{array}{l}\text { Not accepted (medical } \\
\text { decision) }\end{array}$ \\
\hline Noncompliance & $\begin{array}{l}\text { Enteric coated aspirin prescribed for } \\
\text { patients with nasal tube }\end{array}$ & C & Replace for the chewable form & Accepted \\
\hline \multicolumn{5}{|c|}{ Patient Medical Record 4923104} \\
\hline Dosage too low & Glucose: $174 \mathrm{mg} / \mathrm{dL}$ & B & $\begin{array}{l}\text { Increasing the frequency of aspartate } \\
100 \mathrm{U} \text { insulin / } \mathrm{mL} \text { to } \mathrm{q} 6 \mathrm{~h}\end{array}$ & Accepted \\
\hline Adverse drug reaction & $\begin{array}{l}\text { IV pantoprazole prescribed to } \\
\text { patient receiving oral medications }\end{array}$ & A & Change IV pantoprazole to oral & Not accepted (discharged) \\
\hline \multicolumn{5}{|c|}{ Patient Medical Record 979720} \\
\hline Adverse drug reaction & Glucose: $188 \mathrm{mg} / \mathrm{dL}$ & B & $\begin{array}{l}\text { Replace } 5 \% \text { dextrose fot } 0.9 \% \text { saline } \\
\text { solution for dilution of vancomycin }\end{array}$ & Accepted \\
\hline Adverse drug reaction & $\begin{array}{l}\text { Absence of therapeutic drug } \\
\text { monitoring collection after the } 5 \text { th } \\
\text { dose of vancomycin }\end{array}$ & B & $\begin{array}{l}\text { Collect blood sample in vancomycin } \\
\text { trough ( } 30 \text { minutes before the next } \\
\text { dose) }\end{array}$ & $\begin{array}{l}\text { Not accepted (collection was } \\
\text { not performed on vancomycin } \\
\text { trough) }\end{array}$ \\
\hline
\end{tabular}

Table 1: Description of drug therapy problems identified per patient, according to their etiology, description of pharmaceutical interventions and clinical outcomes observed during August $20^{\text {th }}$ to $24^{\text {th }}, 2012$, at the Surgical Intensive Care Unit. 
To ensure that the patient MR \#742896 receive your medicine at optimal dose spacing, it was important that the scheduling of the drug to be $\mathrm{q} 12 \mathrm{~h}$ instead of bid, because if the patient is in a procedure, and metoprolol scheduled $\mathrm{q} 12 \mathrm{~h}$, as soon as the patient returns from the procedure will receive a dose of medicine, and this will not be ignored by the nursing staff. The intervention was accepted.

Studies showed that the rate related to stress-induced ulceration mortality reaches $50 \%$ of ICU patients [21]. This type of ulcer lead to clinically significant bleeding in $3-6 \%$ of patients, clinically characterized, 24 hours after the onset of ulceration, by decrease equal or greater than $20 \mathrm{mmHg}$ in systolic blood pressure when the patient is bedridden; increased heart rate by 20 beats/min and decreased systolic blood pressure by $10 \mathrm{mmHg}$ when the patient is upright; and also, a decrease in hemoglobin of at least $2 \mathrm{~g} / \mathrm{dL}$ [22].

Bleeding occurs because at the time of ICU admission, the patient feels stressed, cornered and there is activation of the sympathetic nervous system, with increased release of catecholamines and procytokines, which in turn will leads to displacement of blood from the gastrointestinal (GI) tract to organs related with escape, such as muscles and brain. When prolonged, this gastric hypoperfusion and consequent reduction in oxygen supply decrease the secretion of bicarbonate and mucus in the stomach, besides reducing gastric motility. These effects of the GI tract, make it more susceptible to the corrosive action of pepsin and other bile acids, leading to ulceration and constant degradation of formed clots [22].

Once the ulcer is formed in a patient at ICU, the probability of sepsis or multiple organ failure is imminent, may lead him to death. Therefore, to prevent the worsening of a clinical picture to this point, prophylaxis is the most effective way.

In these cases, cimetidine remains the only $\mathrm{H} 2$-receptor agonist approved by the Food and Drug Administration (FDA) for the prevention of gastrointestinal bleeding in critical care patients. The scheme approved by the FDA is $50 \mathrm{mg} / \mathrm{h}$ IV continuous infusion, however, in practice, intermittent bolus infusion is more used [22]. A comparative study of continuous IV cimetidine versus oral omeprazole resulted in a significant reduction of gastrointestinal bleeding with omeprazole compared with cimetidine [23]. Therefore, prevention is done with the use of proton pump inhibitors.

MR \#4924432 and MR \#4923104 patients were able to receive oral medication, but were still receiving proton pump inhibitor, pantoprazole, intravenously. For economic reasons and to prevent possible infections and formation of biofilms [24], it is practice prioritize oral instead of parenteral, when it is possibility. However, patients were discharged and would not need prophylaxis any more.

The MR \#4348201 patient's metoprolol status was scheduled and PRN. In this case, the scheduled medicine should be evaluated as to dosage, or even combined another antihypertensive drug (different mechanism of action), if it was not controlling blood pressure effectively [25,26]. But it should not be in PRN in cases of hypertension, because the likelihood of drug therapy problems would be increased.

Medicines for blood pressure control are extremely important to the health and welfare of the patient, it must always be on scheduled status. The metoprolol prescription of patient MR \#4918096, was PRN, which could lead to drug therapy problems such as rebound hypertension due to the inconsistent use of the drug [25].
Drugs that have an irritant effect on the stomach, such as acetylsalicylic acid can be coated with a substance that will dissolve only in the small intestine, when crushed to be able to pass through the nasogastric tube of patient MR \#4918096, lose this property, thus having a different effect than expected [27]. The suggestion of the exchange for chewable presentation, demonstrates how important it is the presence of the clinical pharmacist in the round, along with other professionals in the multidisciplinary team, because it was possible that this patient had worsening of their clinical condition by ineffectiveness of the drug chosen or adverse drug effects. Furthermore, Vikitil8 demonstrated that the presence of clinical pharmacist during rounds, gives greater confidence to other professionals of the multidisciplinary team, increases the percentage of acceptance of suggested interventions.

The MR \#4923104 patient had diabetes mellitus and insulin use was for glycemic control and prevention of infections [28]. But the insulin was not controlling glicemia as required; a greater amount of insulin was necessary, thus the suggestion was to increase the administration dose to q6h. Glucose decreased from $174 \mathrm{mg} / \mathrm{dL}$ to $153 \mathrm{mg} / \mathrm{dL}$.

Patient safety is a priority for all employees, especially for pharmacists, since despite all precautions, some medications may be unsafe for certain patients, as was the case of the patient MR \#979720, with severe infection, requiring, therefore, vancomycin, which could be diluted in 5\% dextrose. Apparently the diluent could be raising the patient's blood sugar level, corresponding to a therapeutic problem. The change of blood glucose level by diluent is still a controversial topic, but has been reported in hospitalized patients [29].

The drugs used in the ICU or operating room may also induce hyperglycemia such as exaggerated administration of epinephrine and norepinephrine, resulting in insulin resistance by increasing gluconeogenesis. Hyperglycemia has been hypothesized that prevent the normal physiological responses against infections: mechanisms including inactivation of the complement system, uneven adhesion of granulocytes, impaired phagocytosis (occurs at even lower levels than $200 \mathrm{mg} / \mathrm{dL}$ ), delayed and decreased Oxidative "Burt" chemotaxis [28].

Hyperglycemia is common in ICU patients, regardless of whether these patients have diabetes mellitus, and is associated with increased morbidity and mortality [28]. Therefore, for the case of a patient who underwent surgery, and presents a serious infection, the blood glucose level should be controlled. It was suggested that the amount of glucose delivered to the patient MR \#979720 was reduced and the solvent was replaced for normal saline, given its physical and chemical compatibility [29]. After the intervention, the patient's blood glucose decreased from $188 \mathrm{mg} / \mathrm{dL}$ to $118 \mathrm{mg} / \mathrm{dL}$.

The main antibiotics used at U.S. that requires therapeutic drug monitoring are vancomycin, when administered as IV, and gentamicin. These drugs, as are broad coverage antibiotics, are in general the first medical choice, while they wait the results of susceptibility testing. According to the pharmacokinetic parameters of these drugs, the measurement of trough phase is the easiest way to know the effectiveness of therapy compared to assessment by the ratio of the area under the curve on minimum inhibitory concentration (AUC/MIC) clinical form, as in this case many samples of the patient's blood is required. Thus, determine the concentration in the trough phase is the closest parameter to ensure that the patient is receiving the minimum appropriate amount of antibiotic to fight infection, and reduce the phenomenon of bacterial resistance [30]. 
The suitable serum levels at trough phase are the minimum antibiotics amount to combat infecting bacteria and depend on the antibiotic and the severity of the infection. For vancomycin serum trough levels recommended range between $15-20 \mathrm{mg} / \mathrm{mL}$ for serious infections (bacteremia, endocarditis, osteomyelitis and meningitis and pneumonia) [30-32].

There is evidence that, for patients in the ICU, is economically viable monitoring of vancomycin levels in an attempt to avoid nephrotoxicity, particularly those who are also receiving other potentially nephrotoxic drugs, as well as cancer patients. This fact demonstrates that the presence of a clinical pharmacist brings benefits not only to the health of patients, but also for the health service by reducing new clinical problems, becoming an economic benefit [30].

The MR \#979720 patient has not had vancomycin levels dosed since the fourth dose of the antibiotic. However, the intervention was applied incorrectly, because to obtain the measurement at trough phase is necessary that the blood collection be made 30 minutes before the next dose of vancomycin [30].

There was a predominance of drug therapy problems related to unnecessary pharmacotherapy, different from what was found by Reis [33] in Brazil, where the use of unnecessary or inappropriate medication is the second most common error, being dose errors the first.

The emergence of a new drug therapy problem related to the use of unnecessary medication can prolong the stay of these patients in the ICU, a fact that is financially inefficient for the hospital, to the patient, the health insurance of the patient and/or the government [8]. Although no situation of category F (NCCMERP) have been identified, the presence of the pharmacist in the multidisciplinary team allows identification and interception of medication errors.

\section{Conclusion}

The prevalence drug therapy problems in critically ill patients demonstrated that to each patient, at least two drug therapy problem can be prevented and/or remedied by clinical pharmacists. Data demonstrate that this professional can contribute to the security and proper use of medications, as the trigger for intensive monitoring helps in early detection of drug therapy problems, therefore patient safety.

\section{References}

1. Mastroianni PC, Machuca M (2013) Farmacovigilância: problemas de segurança e inefetividade relacionados ao uso de medicamentos. In: Mastroianni PC, Varallo FR (eds) Farmacovigilância para o uso correto de medicamentos. Artmed, Porto Alegre.

2. Cipolle R J, Strand LM, Morley PC (2012) Pharmaceutical Care Practice. The Patient-Centered Approach to Medication Management. Terceira edição. The McGraw-Hill, Minnesota, E.U.A.

3. WHO (2002) The importance of pharmacovigilance- Safety Monitoring of Medical Products. WHO, Geneva.

4. MacLaren R, Bond CA (2009) Effects of pharmacist participation in intersive care units on clinical and economic outcomes of critically ill patients with thromboembolic or infarction-related events. Pharmacotherapy 29: 761-768.

5. Kaboli P J, Hoth AB, McClimon BJ, Schnipper JL (2006) Clinical Pharmacists and Inpatient Medical Care. A systematic review. Arch Intern Med 166: 955-964.
6. Jiang SP, Zhu ZY, Ma KF, Zheng X, Lu Xy (2013) Impact of pharmacist antimicrobial dosing adjustments in septic patients on continuous renal replacement therapy in an intensive care unit. Scand J Infect Dis 45: 891-899.

7. Jiang SP, Zhu ZY, Wu XL, Lu XY, Zhang XG, et al. (2014) Effectiveness of pharmacist dosing adjustment for critically ill patients receiving continuous renal replacement therapy: a comparative study. Ther Clin Risk Manag 3: 405-412.

8. Viktil KK, Blix SH (2008) The Impact of Clinical Pharmacists on DrugRelates Problems And Clinical Outcomes. Basic Clin Pharmacol Toxicol 102: 275-280.

9. Anthes AM, Haristein LM, Smithburger PL, Seybert AL, Kane-Gil SL (2013) Improving adverse drug event detection in critically ill patients through screening intensive care unit transfer summaries. Pharmacoepidemiol Drug Saf 22: 510-516.

10. NCCMERP (1996) Medication Error Index. National Coordanating Council for Medication Erros Reporting and Prevention.

11. Hanks S (2008) The Law of Unintended consequences. When pain management leads to medication errors. PT 33: 420-425.

12. Pain management. Joint Commission. JCAHO.

13. Honiden S, Siegel MD (2010) Analytic reviews: managing the agitated patient in the ICU: sedation, analgesia, and neuromuscular blockade. J Intensive Care Med 25: 187-204.

14. McPherson ML (2008) Strategies for the management of opiod-induced adverse effects. Adv Stud Pharm 5: 52-57.

15. The Joint Commission Sentinel Event Alert. JCAHO.

16. Lexi Comp ${ }^{\oplus}$. Lexi-Drugs: Metoprolol. Online Lexi.

17. Lexi Comp ${ }^{\star}$. Lexi-Drugs: Labetalol. Online Lexi.

18. Lexi Comp ${ }^{\oplus}$. Interactions: Labetalol and Metoprolol. Online Lexi.

19. Lexi Comp ${ }^{\oplus}$. Lexi-Drugs: Hydromorphone. Online Lexi.

20. Cook DJ, Fuller HD, Guyatt GH, Marshall JC, Leasa D, et al. (1994) Risk factors for gastrointestinal bleeding in critically ill patients. N Engl J Med 330: 377-381.

21. Martindale RG (2005) Contemporary Strategies for the Prevention of Stress-Related Mucosal Bleeding. Am J Health-Syst Pharm 62: S11-17.

22. Conrad SA, Gabrielli A, Margolis B, Quartin A, Hata JS, et al. (2005) Randomized, double-blind comparison of immediate-release omeprazole oral suspension versus intravenous cimetidine for the prevention of upper gastrointetinal bleeding in critically ill patients. Crit Care Med 33: 760-765.

23. Kuper KM (2008) Intravenous to oral therapy conversion. In: Text Book of Competence Assessment Tools for Health-System Pharmacies. (4thedn), ASHP.

24. Brazilian Society of Cardiology, Brazilian Society of Hypertension; Brazilian Society of Nephrology (2010) VI Diretrizes Brasileiras de Hipertensão. Arq Bras Cardiol 17: 1-64.

25. James PA, Oparil S, Carter BL, Cushman WC, Dennison-Himmelfarb C, et al. (2014) 2014 Evidence-based guideline for the management of high blood pressure in adults. Report from the panel members appointed to the eighth joint national committee (JNC 8). JAMA 311: 507-520.

26. Serrumbia AMB (2000) Administração de Fármacos por Sonda Nasogástrica. Revista Portuguesa de Medicina Intensiva 9: 17- 23.

27. Lewis KS, Kane-Gill SL, Bobek MB, Dasta JF (2004) Intensive Insulin Therapy for Critically Ill Patients. The Annals of Pharmacotherapy 38: 1243-1251.

28. Krajicek BJ, Kudva YC, Hurley HA (2005) Potentially important contribution of dextrose used as diluent to hyperglycemia in hospitalized patients. Diabetes Care 28: 981-982.

29. Lexi Comp ${ }^{\oplus}$. Lexi-Drugs: Vancomycin. Online Lexi.

30. Ryback M, Lomaestro B, Rotschafer JC, Moellering R Jr, Craig W, et al. (2009) Therapeutic monitoring of vancomycin in adult patients: A consensus review of the American Society of Health-System Pharmacists, the Infectious Diseases Society of America, and the Society of Infectious Diseases Pharmacists. Am J Health-Syst Pharm 66: 82-98. 
Citation: Alves GMR, Varallo FR, Lucchetta RC, Mastroianni PC (2014) Role of the Clinical Pharmacist in Detection of Drug Therapy Problems in Critically Inpatients: Experience Report. J Pharmacovigilance 2: 139. doi:10.4172/2329-6887.1000139

Page 6 of 6

31. Nailor MD, Sobel JD (2009) Antibiotics for Gram-Positive Bacterial Infections: Vancomycin, Teicoplanin, Quinupristin/Dalfopristin, Oxazolidinones, Daptomycin, Dalbavancin and Telavancin. Infect Dis Clin N Am 23: 965-982.

32. The Medical Letter Online (2009) Vancomycin Dosing and Monitoring The Medical Letter on Drugs and Therapeutics 51: 25.
33. Reis WCT, Scopel CT, Correr CJ, Andrzejevski VMS (2013) Análise das intervenções de farmacêuticos clínicos em um hospital de ensino terciário do Brasil. Einstein 11: 190-196. 